\title{
Local capacity and resilience to flooding: community responsiveness to the community ratings system program incentives
}

Abdul-Akeem Sadiq, Douglas Noonan

\section{Introduction}

Historically, flooding has resulted in considerable losses, both in property damage and lives lost, throughout the world. According to a report by Guha-Sapir et al. (2013), 53 percent of the total number of victims of natural disasters worldwide in 2012 was victims of floods. Data from the International Disaster Database (2013) likewise show that flooding affects millions of people ${ }^{1}$ and causes billions of dollars in damage yearly ${ }^{2}$. The United States annually averaged 95 fatalities and $\$ 8.20$ billion in damages from floods between 1982 and 2011 (National Weather Service (NWS) 2013). In the United States, flooding makes up 80 percent of presidentially declared disaster losses (Landry and Li 2012). In the light of changing climates and increases in precipitation and sea level rise (Intergovernmental Panel on Climate Change (IPCC) 2012; Ludy and Kondolf 2012; Kousky et al. 2013), and commensurate increases in flood damages (Major et al. 2014), there is a concomitant need to manage flood disaster risks.

Flood risk management, like so many environmental concerns, heavily involves communities and collective action as necessary parts of the problems and the solutions. The Community Ratings System (CRS) was designed to encourage communities to go beyond the National Flood Insurance Program (NFIP) requirements and build local capacity to address flood risks. In so doing, communities can be more resilient towards future flood disasters. As the CRS is a policy tool targeted at community-level responses, unlike regulations or taxes levied on individuals or firms, the CRS offers a compelling context in which to study the capacity of communities to undertake collective action in response to top-down incentive schemes. Flooding represents an environmental challenge that inherently affects communities, and improved ways to overcome collective action problems may become essential for community resilience as climate change dramatically increases flood risks (Kousky et al. 2013) and brings new threats.

Communities participating in CRS can reduce their flood risks while at the same time enjoy discounted premiums (up to 45\%) on federally required flood insurance commensurate to their community's CRS score (see Table 1). Participant communities are grouped into different classes based on their CRS scores (class 1 to 9), which in turn determines the amount of premium reduction they receive. The peculiar, tiered nature of this incentive scheme presents an

\footnotetext{
1 “EM-DAT: The OFDA/CRED International Disaster Database, University catholique de Louvain, Brussels, Bel.” Available at: http://www.preventionweb.net/english/hazards/statistics/?hid=62.

2 “EM-DAT: The OFDA/CRED International Disaster Database, University catholique de Louvain, Brussels, Bel.” Available at: http://www.preventionweb.net/english/hazards/statistics/?hid=62.
}

This is the author's manuscript of the article published in final edited form as: 
excellent opportunity to better understand how communities respond. This tiered incentive structure of the CRS program can distort participating communities' efforts to reduce their flood risks and become more resilient to future flood disasters. In theory, relative to having no subsidy, the CRS incentives should induce more flood mitigation activity by some participating communities while other participants merely receive subsidies for activity they would have done anyway. In order to evaluate the performance of CRS vis-à-vis its tiered incentive structure, we investigate (1) the extent to which communities are responsive to CRS incentives, and (2) the characteristics of those communities that are responsive to CRS incentives. By responsive communities, we mean communities that are changing their behaviors as a result of the nonlinear incentive design of CRS (e.g., engaging in more flood mitigation activity), regardless of whether that response was intended or not. The CRS may encourage more flood management effort, and it might also favor certain types of activities with an implicit opportunity cost in terms of other policy alternatives. For example, responsive communities might select a disproportionate number of less expensive or "passive" activities (Brody et al. 2009; Sadiq 2010) in order to achieve a greater CRS subsidy. Such responsive behavior of communities may indicate inefficiencies in the current, tiered CRS structure (Zahran et al. 2010). Inefficiencies such as this could ultimately undermine the effectiveness of the CRS program and hinder communities' ability to build the local capacity needed to reduce their flood risks. In short, the incentive scheme created by the CRS will influence its ultimate effectiveness, create opportunities for participating communities to undertake certain behaviors, and potentially distort community responses in unintended ways.

In the following section, we give a brief background on the CRS program and then examine the literature on CRS participation. Next, we present our theoretical model and discuss the methodology. We investigate communities' responsiveness by examining statistical discontinuities around CRS tiers using national data on historical CRS participation, local flood risks, demographics from the Census, and government characteristics from the Census of Governments. Then we present our findings and discuss their implications. We conclude with policy recommendations for increasing local capacity and enhancing community resilience.

\subsection{The Community Rating System}

Due to increasing disaster losses in the US, the US Congress established the NFIP through the passage of the National Flood Insurance Act of 1968. Communities can participate in the NFIP by adopting and enforcing floodplain management ordinances in exchange for federally backed flood insurance (Federal Emergency Management Agency (FEMA) 2011). NFIP also developed the Flood Insurance Rate Map (FIRM), which depicts the base flood elevations, flood zones, and floodplain boundaries of the nation's communities. These maps help homeowners, renters, and insurance companies identify flood risk (FEMA 2002). Recognizing that buildings constructed prior to the adoption of FIRM were not likely to have known about flood hazard risks, pre-FIRM buildings receive subsidized insurance rates. However, a community participating in CRS has to 
make sure that new construction abides by the existing community floodplain management ordinances (FEMA 2002).

The Community Rating System was implemented in 1990 to enhance incentives for communities to go beyond the NFIP requirements to address flood risks. The program has three main objectives; reduce flood losses, strengthen accurate insurance ratings, and foster awareness of flood insurance (King 2013). When communities participate in CRS, they not only reduce their flood risks they also enjoy discounted premiums (up to 45\%) on federally required flood insurance, respective to their community's CRS score. To date, over 1,200 communities from all 50 states are participating voluntarily in the CRS program, achieving a wide range of ratings (FEMA 2013a). Credited activities to be completed by communities fall into 4 major categories: public information activities, mapping and regulations, flood damage reduction activities, and warning and response (see Table 2). Public information activities promote the purchase of insurance, advise people about their flood hazards, and provide information on how to reduce risks. Mapping and regulation activities increase the protection for new development, while flood damage reduction activities address the risks present in current structures and infrastructure. Lastly, the warning and response activities are those that prepare communities to respond during flood events (FEMA 2013a).

Table 1 - CRS Classes, Credit Points, and Premium Discounts Based on Location In or Outside Special Flood Hazard Areas (SFHA).

\begin{tabular}{cccc}
\hline CRS Class & Credit Points & \multicolumn{2}{c}{ Premium Reduction } \\
\cline { 3 - 4 } & & In SFHA (\%) & Outside SFHA (\%) \\
\hline 1 & $4,500+$ & 45 & 10 \\
2 & $4,000-4,999$ & 40 & 10 \\
3 & $3,500-3,999$ & 35 & 10 \\
4 & $3,000-3,499$ & 30 & 10 \\
5 & $2,500-2,999$ & 25 & 10 \\
6 & $2,000-2,499$ & 20 & 10 \\
7 & $1,500-1,999$ & 15 & 5 \\
8 & $1,000-1,499$ & 10 & 5 \\
9 & $500-999$ & 5 & 5 \\
10 & $0-499$ & 0 & 0 \\
\hline
\end{tabular}

Source: FEMA (2013b).

Table 2 - Credit Points Awarded for CRS Activities.

\begin{tabular}{lcc}
\hline Activity & $\begin{array}{c}\text { Maximum Possible } \\
\text { Points }\end{array}$ & $\begin{array}{c}\text { Percent of Communities } \\
\text { Credited* }\end{array}$ \\
\hline Passive (Information-based) Activity & & \\
\hline 300 Public Information Activities & 116 & $100 \%$ \\
310 Elevation Certificates & 90 & 93 \\
320 Map Information Service & 360 & 90 \\
330 Outreach Projects & 80 & 68 \\
340 Hazard Disclosure & &
\end{tabular}




\begin{tabular}{lcc}
350 Flood Protection Information & 125 & 92 \\
360 Flood Protection Assistance & 110 & 41 \\
\hline Active (Non-information-based) Activity & & \\
\hline 400 Mapping and Regulations & & $50 \%$ \\
410 Floodplain Mapping & 2,020 & 68 \\
420 Open Space Preservation & 2,042 & 98 \\
430 Higher Regulatory Standards & 222 & 87 \\
440 Flood Data Maintenance & 755 & 83 \\
450 Stormwater Management & & $43 \%$ \\
500 Flood Damage Reduction Activities & 622 & 23 \\
510 Floodplain Mgmt. Planning & 1,900 & 11 \\
520 Acquisition and Relocation & 1,600 & 78 \\
530 Flood Protection & 570 & $37 \%$ \\
540 Drainage System Maintenance & & 0 \\
600 Warning and Response & 395 & 0 \\
610 Flood Warning and Response & 235 & \\
620 Levees & 160 & \\
630 Dams &
\end{tabular}

*Includes communities credited partially. Source: adapted from FEMA (2013b).

\subsection{Factors Influencing CRS Participation}

This study investigates how communities respond to top-down incentives to promote community resilience to flood risks. Overcoming collective action problems to provide community flood resilience - a classic example of a common-pool resource (Ostrom 1990) - poses one of the most fundamental challenges to environmental policy (Mansbridge 2013). The CRS context represents a case of a national government overtly subsidizing local governments to provide for the flood resilience commons (Mansbridge 2013). The CRS program resembles conventional environmental policy as a top-down directive or subsidy, but it departs from typical US federal environmental policy in that it bypasses state governments, directly targets local governments, and ostensibly promotes provision of local commons-community flood resilience. Even as major programs like the NFIP emphasize insurance for private property owners (FEMA 2011), Landry and Jahan-Parvar (2011), Petrolia et al. (2013), and Poussin et al. (2014) focus on flood mitigation activities of individual households, but did not examine how CRS incentives affect what participating communities do. Much less is known about flood mitigation activities by communities. Through the NFIP and CRS, the federal government encourages local communities to implement flood risk management measures by providing commensurate premium reductions (to homeowners, an even smaller units), but also risks some actors behaving strategically to take advantage of the CRS. This might result in unintended communities responding (e.g., those facing lower flood risks) or communities responding in unintended ways (e.g., receiving subsidies for activities that would have been done anyway).

Researchers have examined the factors associated with communities that participate in the CRS program. For instance, Brody et al. (2009) use the CRS as a case study to understand policy learning for flood mitigation, while Posey (2009) uses the CRS as a proxy for adaptive 
capacity and examines whether the socio-economic status of individuals in a community was a determinant of adaptive capacity. Zahran et al. (2009) study the correlation between flood insurance purchase by households and CRS participation by local governments in Florida, calling for future research into causes of CRS participation. Furthermore, Landry and Li (2012) examine the influence of local capacity, hydrological risk factors, and flood experience on community hazard mitigation decisions (i.e., CRS participation) in North Carolina counties. Finally, Noonan and Sadiq (forthcoming) examine why some communities choose to participate in CRS and other do not, and the predictors of CRS scores conditional on participation. They found that local capacity, flood risk factors, socio-demographic characteristics, and political economy factors are important determinants of CRS participation. They also found that the predictors of CRS participation are not the same drivers of CRS scores. This literature points to a close relationship between community flood mitigation efforts and demographics, property values, and flood risk.

This study contributes to this literature on community flood risk management and builds upon the work of Zahran et al. (2010). These researchers analyze the relationship between the nonlinear incentive structure of CRS and observed changes in CRS points and find incentive responsiveness by some local jurisdictions in Florida. Furthermore, they conclude that communities may be behaving strategically in order to take advantage of the CRS program by emphasizing "easy gains" in the CRS and neglecting some floodplains to cut mitigation costs. We heed their call for a multi-state study to produce more generalizable results and for more attention to the implications of nonlinear incentive structures and community responsiveness. National studies of the CRS are lacking, and previous studies have not been able to isolate the effect of the CRS incentives on flood mitigation from other (latent) demand for flood mitigation in that community; this study leverages the nonlinearity in the CRS incentive scheme to identify which CRS participants are indeed responsive to the CRS incentives in determining the flood mitigation efforts. Thus, our study extends Zahran et al. (2010) by identifying the extent of communities' responses to federal incentives to increase community flood mitigation (rather than just receive the subsidy for no additional effort) and describing how community characteristics differ between responsive and nonresponsive jurisdictions across a national sample.

\section{Methods}

\subsection{Tiered incentive schemes}

A key feature of the CRS is its nonlinear or "tiered" incentive scheme, where subsidies (flood insurance discounts) increase along intervals of Credit points earned by a community. These kind of tiered policy instruments are common, although their implications have not received commensurate attention (Sallee and Slemrod 2012). The US Gas Guzzler Tax, green building and appliance certification programs, and nonattainment areas for air pollution are all prominent environmental examples of incentives designed to accrue discontinuously, once a quantitative threshold has been crossed. Such designs provide particular incentives with predictable behavioral consequences, relative to no policy at all and relative to a continuous, linear incentive scheme (e.g., emissions taxes). Appendix B in the Supplementary Materials details a theory of these tiered incentive systems and how it applies to the CRS context. 
In short, the federal subsidy leads to a new distribution of flood mitigation activity. Relative to a (revenue-neutral) scenario with a linear subsidy, some communities will opt to "upgrade" to the next tier while others will "downgrade" and achieve nothing more than the minimum standard to reach their current tier. (See Fig. B1 in Appendix B.) In this comparison, the net effect of the CRS's tiered incentive system is theoretically ambiguous and depends on the distribution of the net benefits of upgrading versus downgrading. The post-policy distribution of CRS Credit points should completely bunch up just above the tier thresholds. Arguably the more important comparison for evaluating the CRS is between the tiered CRS system and a policy with no subsidies. Appendix B discusses the theoretical implications in greater detail. Relative to scenarios with no subsidy, community efforts are either greater or unchanged (no downgrading), depending on that community's particular (economic, political, other) calculus. The post-policy distribution of Credit points should also bunch just above tier thresholds, although some communities will persist in the points interval in the middle of their tier because the net upgrade costs outweigh the incremental subsidy gain (see Fig. A2 in the Appendix).

The distributional implications of the CRS's tiered incentive scheme are essential here. The discontinuous subsidy makes it possible to identify the responsive communities. This is the first theoretical prediction to be tested in the empirical analysis. Theory predicts both bunching just above thresholds by upgrading communities and some mid-tier observations from communities unaffected by the incentive. Thus, identifying the extent to which communities are bunching above thresholds - and how those communities differ - describes how much of an impact the CRS has had on community mitigation behavior. This is the second hypothesis to follow from the theoretical discussion (see Appendix B). The empirical analysis tests whether communities bunching above thresholds - the responsive communities - will systematically differ from those just below thresholds.

\subsection{Regression Discontinuity Approach}

Since its introduction by Thistlethwaite and Campbell in 1960, RD design has been used in various domains (e.g., education, environment, health) to ascertain program or policy effectiveness (Thistlethwaite and Campbell 1960; Lee and Lemieux 2010; Matisoff et al. 2014; Noonan 2014). The basic premise behind an RD design is to examine treatment effects, where receiving treatment depends on some factor $(x)$ exceeding an arbitrarily set threshold $(t)$, by looking at observations with just above and just below the threshold. Such a comparison identifies the causal effect of treatment by leveraging the seemingly random assignment of treatment to observations just above threshold rather than those, otherwise equivalent, observations just below. The effect of a large incremental discount in flood insurance premiums under the CRS would, in principle, be identifiable via an RD approach because these CRS tiers are based on arbitrary threshold scores. Effects of CRS subsidies on outcome variables (e.g., flood damages suffered, new floodplain development) could be readily estimated under the assumption that communities cannot precisely manipulate their CRS points around the thresholds. ${ }^{3}$ Otherwise, causal effects remain elusive as communities non-randomly select into subsidy "treatment" levels.

\footnotetext{
${ }^{3}$ Although, communities can choose which programs to implement and, consequently, have some control over the CRS scores they obtain, the ultimate decision on their actual and final CRS scores is in the hands of a CRS specialist
} 
An advantage of RD design, especially relative to other approaches like instrumental variables, is that the randomness of the assignment above and below the threshold can be tested (Lee and Lemieux 2010). Standard RD approaches can be applied to the CRS context to assess whether communities are systematically sorting into the treatment. If the communities scoring just above the point threshold associated with, say, Class 8 looked no different than those scoring just below Class 8, then more confidence might be given to basing causal inferences on a comparison of outcome variables between those two community types. Conversely, if those two community types had markedly different baseline conditions, then we should be suspicious of ascribing causality to the CRS nonlinear incentives.

More importantly for this study, however, detecting a story about self-selection in this context implies systematic responsiveness at the community level and illuminates how the CRS is spurring responsiveness from different communities. This is nontraditional use of RD, where identifying causal effects is typically the aim. Here, we emphasize tests common to RD design that allow us to identify systematic patterns in CRS participation around thresholds. Even though self-selecting around thresholds means we cannot make causal inferences about CRS participation on outcome variables that the CRS might seek to influence (e.g., flood losses, resiliency), we can infer which and how communities respond to the nonlinear subsidy treatment. The portfolio of flood mitigation activities for communities cannot simply be said to be caused by CRS, as some activities would have been done regardless. Rather, spikes in frequencies of certain activities (e.g., information provision) at thresholds are associated with those responsive, upgrading communities. We can show participants' self-selection in response to CRS incentives, something that studies of CRS's causal effects would do well to address.

The test that we use to detect whether variables differ on either side of a threshold comes from Porter (2003). This nonparametric approach estimates, for each variable of interest, it's right and left limits at the threshold(s) using local linear regressions. ${ }^{4}$ The difference $(\alpha)$ between the limits taken from the right and taken from the left reveal the presence of a discontinuity, in our case implying some strategic "sorting” by communities around the tier thresholds. Alternative bandwidths for the kernel-weighted regressions are selected and tested, reflecting a standard bias-versus-precision tradeoff. Narrower bandwidths should be subject to less bias from underlying trends in the data, but they also leverage less data in the analysis and thus possess less precision. Larger bandwidths make use of more data but may invite influences, other than the sharp discontinuity itself, to affect the results by looking further beyond the threshold. Our analysis uses relatively narrow bandwidths of 20, 25, and 30, ${ }^{5}$ reporting the middle value in the main analysis (and relegating the sensitivity check for larger and smaller bandwidths to an appendix). Further, we conduct numerous falsification tests to see if these tests can detect discontinuities at "interior" CRS scores (e.g., 723) for which there should be no threshold or discontinuity. Appendix A reports the results from one sample falsification test.

after implementation. This argument is corroborated by the CRS Coordination Manual: “Only the final, verified credit calculated by the ISO/CRS Specialist after the verification visit determines a community's total points.” (FEMA 2013: 110-7)

${ }^{4}$ Basically, a kernel-weighted local regression is fit using only data to the left of the threshold, another kernelweighted local regressions is fit using only data to the right, and the difference in their predicted values at the threshold is $\alpha$.

${ }^{5}$ Zahran et al. (2010) use 50 points above thresholds as a cutoff to capture those relevant observations. 


\subsection{Data}

Four data sources are combined to inform the analysis. Data on CRS participation is obtained from the 2013 CRS Coordinator's Manual (FEMA 2013b). Underlying flood risk data from FEMA (1996) offer very high resolution (1 km grid cell) rankings of flood risk (on a 0-100 scale) based on data that largely predate the start of the CRS program. Information about the population and housing stock of communities is obtained from 1990 block-group level Census data from US Census Bureau (1993). Furthermore, information about government expenditures and revenues is taken from the 1992 Census of Government (1992), the earliest available Census data on local governments' finances. The unit of analysis for this study is the community participating in the CRS, which includes cities, villages, towns, townships, other incorporated places as well as counties. Each community is mapped onto flood risk and Census data and, non-county communities are matched to a host county for consistency in analysis. All variables are taken from 1990 or as close to that date as possible in order to better match to conditions existing before the start of the CRS program. An effective CRS program might cause changes to communities' flood risk, housing stock, and other socio-economic indicators. Hence using historical measures rather than current ones avoids this endogeneity concern and sharpens the interpretation that these community attributes are driving responsiveness to CRS incentives rather than the CRS is causing changes in community conditions. The latter may still be true, but is not tested here.

\subsection{Variables}

The primary variable for this analysis is the total CRS Credit points for each community. Figure 1 shows the distribution of these credit points. The red lines represent classes 9 (500-999 credit points) to 1 (4,400+ credit points). As is evident from glancing at Figure 1, few communities rate better than Class 6 and there is a strong reverse sawtooth wave pattern in the data around the thresholds associated with higher subsidies. Communities eschew point totals just below thresholds and tend to gravitate toward values just above thresholds. It is quite clear from Figure 1 that there is clustering just above the 1,000, 1500, 2000, and 2500 credit thresholds. 


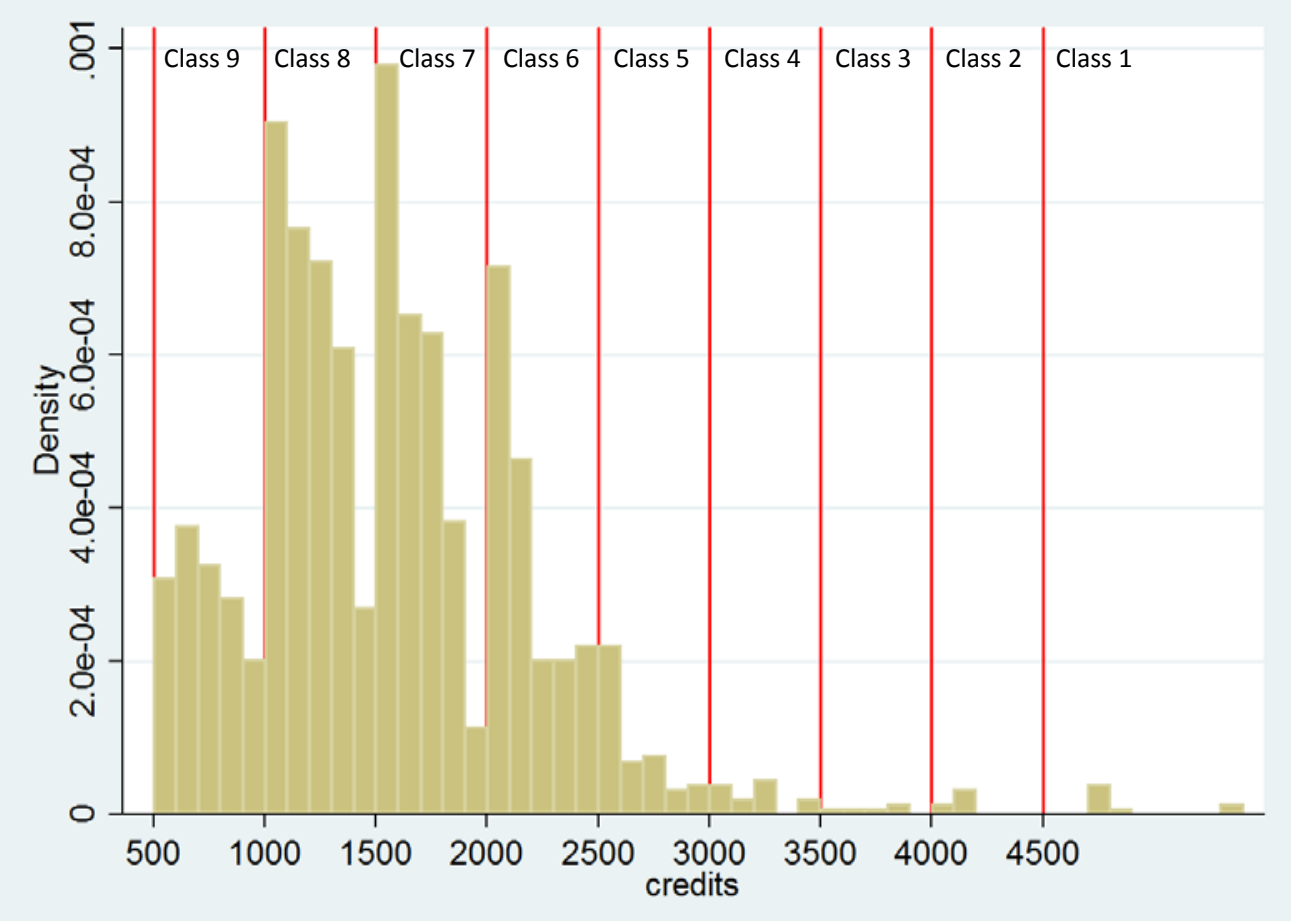

Fig. 1 - Histogram of CRS credits points obtained by CRS Communities.

Following Sadiq's (2010) classification of risk-reducing measures, we group the 18 CRS activities ${ }^{6}$ in Table 2 into active and passive activities to have a better understanding of the responsiveness of communities. Active activities are proactive (non-information) flood control activities undertaken by communities to address flood risks, while passive activities are aimed at informing the public about flood-related issues. Active activities include, but are not limited to structural measures like dam and levee construction, open space preservation, acquisition and relocation, and flood warning and response. These active activities, for the most part, require large capital outlay. On the other hand, passive (information-based) activities include informational items that are designed to educate community residents about the dangers of floods and what residents should do before, during, and after a flood. Examples of passive activities include map information services, hazard disclosure, and flood protection information. Passive activities are relatively cheaper than active activities to implement. As a result, we consider passive activities as "low hanging fruits" (Brody et al. 2009: 926; Landry and Li 2012: 216) that more responsive communities would use as "fillers" to upgrade to a higher CRS class.

In order to understand whether there is a difference in the characteristics of communities just above a class threshold (the theoretically responsive communities) and just below that threshold (the non-responsive communities), we explore communities' demographics, property values, and flood risk. We select these attributes because previous researchers found a significant relationship between them and CRS participation. For example, researchers have found significant and positive relationships between flood risk and CRS participation (e.g., Posey 2009;

\footnotetext{
${ }^{6}$ We did not include the new activity 370 "Flood Insurance Promotions” because we have no information on it.
} 
Zahran et al. 2010; Landry and Li 2012). In addition, researchers have found significant and positive relationship between population density and local flood mitigation (Brody et al. 2009; Zahran et al. 2010) and between housing values and the adoption of flood mitigation measures (Landry and Li 2012). Our study is the first we know of to examine whether government capacity affects CRS responsiveness. In addition to CRS points, the community variables considered in this analysis include:

1. Active Share. This is the proportion of the total CRS points that comes from proactive/noninformation activities. Active program points are the sum of credits from activities 410-630 (see Table 2). We expect communities that appear more responsive to CRS incentives (i.e., just above thresholds) to have a lower Active Share as these communities use CRS credits from passive activities as filler to upgrade CRS classes.

2. Flood Risk. This is the peak mean flood risk in the county. ${ }^{7}$ Communities with high flood risk may be more likely to have undertaken flood mitigation activities, regardless of the CRS, and potentially less likely to be responsive to CRS incentives. Alternatively, they may be more aware of or sensitive to the NFIP (and subsidies) and thus more likely to upgrade.

3. Payroll. From the 1992 Census of Governments, this is the log of the participating jurisdiction's (county or place) per-capita payroll expenses, full-time plus part-time. We expect this measure of local government capacity to positively relate to community responsiveness to CRS incentives.

4. Income. This is the log of county median household income. Wealthier communities may be more likely to be responsive to CRS incentives.

5. Housing Value. This is the log of median housing value for the community. Communities with higher housing values may be less likely to be responsive to CRS incentives if homeowners already undertake personal protective measures against flood (Landry and Li 2012). Conversely, greater property values exposed to flood risk may enhance the value of subsidized insurance premiums and increase responsiveness.

6. Population Density. This is persons per $\mathrm{km}^{2}$. Like for Flood Risk and Housing Value, greater population density implies greater exposure to flood damages and thus the likelihood that communities have already undertaken flood mitigation activities regardless of CRS. In addition to being less sensitive to CRS incentives, they might also face larger upgrading costs in highly developed or "built out” cities.

\section{Results}

To test for discontinuities around the CRS thresholds, each of the program's thresholds is examined per Porter (2003) at various bandwidths for each of the variables. Table 3 reports the main results for the lowest two thresholds $(1000,1500)$ using the moderate bandwidth. ${ }^{8}$ Thresholds for higher classes (above Class 7) with bigger insurance subsidies are not reported here because there were too few observations to permit statistical testing at those levels with

\footnotetext{
${ }^{7}$ Each $1 \mathrm{~km}$ grid cell raster map from FEMA (1996) is mapped to over 200,000 Census block groups to obtain a mean flood risk value for each of these neighborhood-scale units in the nation. Flood Risk is set to the maximum (block-group mean) flood risk value within each county. Other aggregations of localized flood risk measures are, of course, possible. The max-mean function is selected because it provided the strongest and most consistent predictor of overall CRS participation among a sample of 28,147 US places.

${ }^{8}$ Tests for the first, lowest threshold at 500 points are not possible because communities and their CRS scores are not observed if the score falls below 500 .
} 
reasonable bandwidths. There are very few communities in the neighborhood of 2,000 CRS points, and far fewer at higher levels.

Table 3 - Test for Discontinuity at Thresholds 1000 and 1500 (Bandwidth 25)

\begin{tabular}{|c|c|c|c|c|c|c|}
\hline \multirow[b]{2}{*}{ Variable } & \multicolumn{3}{|c|}{$\begin{array}{l}\text { Threshold } 1000 \\
\text { (Bandwidth 25) }\end{array}$} & \multicolumn{3}{|c|}{$\begin{array}{l}\text { Threshold } 1500 \\
\text { (Bandwidth 25) }\end{array}$} \\
\hline & mean & $\alpha$ & $\mathrm{p}$ & mean & $\alpha$ & $\bar{p}$ \\
\hline Active Share & 0.8972 & -0.245 & $0 * * *$ & 0.7730 & -0.097 & 0.122 \\
\hline Flood Risk & 92.8128 & -10.577 & $0.094 *$ & 97.3842 & -5.031 & 0.649 \\
\hline Payroll & 5.0154 & -1.632 & $0.010 * * *$ & 1.9363 & 1.479 & $0 * * *$ \\
\hline Income & 10.3371 & -0.119 & 0.478 & 9.8025 & 0.618 & $0 * * *$ \\
\hline Housing Value & 11.8531 & -0.815 & $0 * * *$ & 10.4656 & 1.13 & $0 * * *$ \\
\hline $\begin{array}{l}\text { Population } \\
\text { Density }\end{array}$ & 2800 & -2200 & $0 * * *$ & 426.0833 & 246.885 & 0.579 \\
\hline
\end{tabular}

Table 3 presents the results of the test for discontinuity at thresholds 1000 and 1500 with a bandwidth of 25. The mean value column indicates the estimated average value of the variable at the threshold, and the $\alpha$ column shows the estimated change in that value associated with crossing the threshold to the right. For instance, the Active Share row suggests that CRS class 9 communities just below the 1,000 point threshold have almost 90 percent of their points from “active” programs, yet CRS class 8 communities just above the 1,000-point threshold have only 65 percent $[(0.8972-0.245) \times 100]$ of their points from active measures. Active Share falls by almost 0.25 at that 1,000 -point threshold. Communities influenced by the tiered incentive at low levels of CRS subsidy tend to do a lot more passive programs. At the 1,500-point threshold, however, the decline in Active Share (hence increase in passive share) is smaller and not statistically significant.

Other community characteristics also differ for those responding to the tiered incentive. At the 1,000-point threshold between Class 9 and Class 8, communities able to receive the $10 \%$ discount had much lower average property values, population densities, and government capacity than those receiving only half that discount. They also tended to face lower peak flood risks. The comparison in estimated median housing values just below $(\$ 140,519)$ and above $(\$ 62,199)$ the 1,000-point threshold suggests a striking disparity in the types of communities seeking the increased subsidy. The lower Payroll and government capacity among responsive communities at this low-level of CRS participation suggests that local government size need not drive community-level flood mitigation efforts. ${ }^{9}$ Income did not look different on either side of the threshold. In short, for participating communities on the lower end of the spectrum of flood resilience efforts, those most responsive to the uptick in insurance subsidies tended to have lower

\footnotetext{
${ }^{9}$ Alternate measures of government capacity were also explored, including total payroll outlays, total property tax revenues, property tax revenues per capita, and capital outlays for sewage, solid waste management, and water transport. Each returned qualitatively the same results.
} 
property values, flood risks, and population densities (i.e., they have less property and life at risk, and they are cheaper to subsidize).

At the 1,500-point threshold between Class 8 and Class 7, however, the results change. Unlike the lower threshold, communities above the 1,500-point threshold had much higher property values than their counterparts in communities scoring just below that threshold. These jurisdictions had larger governments and greater household wealth. Also unlike at the lower threshold, the upgrading communities here had no different densities or flood risks. More generally, the selectivity or sorting by communities is different at different levels of participation. For the higher classes of participants, above Class 7, this analysis generally reveals no significant discontinuities for these variables and at these bandwidths. While it may result from declining statistical power with fewer observations, it might also follow from increasingly random sorting around the thresholds. Figure 1 shows no appreciable bunching at Class 6 and above.

The results for alternative bandwidths (Tables A1 and A2 in Appendix A) indicate a great deal of consistency in results. Both the magnitude of the discontinuity and the statistical significance of the tests tend to be closely aligned with the results shown in Table 3, especially where the effects are statistically significant. For these significant effects, the larger bandwidths tend to attenuate the observed effects (i.e., narrower bandwidth imply larger $\alpha$ values). Accordingly, the results in Table 3 can be seen as somewhat conservative estimates of effect sizes. The falsification tests suggest that there are no discontinuities where we would not expect them.

\section{Discussion}

There are three major results evident from the RD approach to these CRS data. First, communities that respond to the nonlinear, tiered incentives in the CRS program look different than those participating communities that do not. Among participating communities undertaking less flood mitigation, the responsive communities had decidedly lower flood risks, lower property values, ${ }^{10}$ lower government payrolls, and lower population densities. The larger subsidies went to communities that started with less flood risk, less property and population exposed to that risk, and arguably less government capacity. This may reflect the circumstances of moderate flood risk communities, where risks are severe enough to warrant moderate, fairly low-cost flood mitigation efforts. Communities in these circumstances that upgrade in response to CRS are those seeking bargains and more federal support and may face less (political) resistance or severe costs to mitigate more.

Among participants with more flood mitigation, the CRS gave greater subsidies to communities with more resources (more valuable property, more income, bigger government budgets) even though their flood risks did not differ. Here, the self-selection mechanism clearly

\footnotetext{
${ }^{10}$ We also examined the share of housing units in the top-coded value category of $\$ 500,000$ or above. The share of very large, expensive homes in the community also fell discontinuously at the 1000-point threshold. It appeared evenly distributed around the 1500-point threshold.
} 
favors the communities better able to identify and finance the upgrading activities - which might be more costly (and hence less "passive") than the upgrading activities at the 1,000-point threshold. It is also consistent with communities with bigger subsidy benefits (i.e., those with more expensive flood insurance premiums) effectively upgrading to Class 7.

Second, communities that respond to the program's thresholds participate in CRS differently than those participating communities that do not. At lower levels of flood mitigation, responsive communities - the ones upgrading to higher levels of subsidy - tend to adopt substantially more passive CRS activities. If passive programs are less effective at reducing community flood risks, such communities may be more likely to suffer greater disaster losses from floods if upgrading to Class 8 provides reduced insurance premiums that might make those communities behave recklessly with regard to flood risk management (Zahran et al. 2009).

Third, while these results strictly speaking refer to differences in communities above and below thresholds, they speak to larger issues of the community responsiveness to CRS subsidies more generally. As portrayed in the theoretical model (section 2.1), communities can be thought of as having an underlying baseline of flood management effort. The CRS induces a "lumpy" distribution on top of a presumably smooth baseline distribution as some communities upgrade their efforts in order to capture a bigger subsidy. Some communities just accept and enjoy the subsidies associated with their baseline, and they remain well below the next threshold.

More than identifying how common "upgrading” communities are, it also helps to appreciate what they are doing differently to upgrade. At lower levels of CRS participation, the results from this vantage are striking because the communities most responsive to the CRS incentive scheme have less property and life at risk of flood and face lower flood risks. That might make them less expensive to subsidize via the CRS, but it also suggests that the most important target communities may not be reached by the CRS incentives. Further, the fact that upgrading occurs via more passive efforts raises questions about the CRS program's effectiveness in reducing community flood risks, especially amid growing concerns of increased climate change-induced precipitation (IPCC 2012).

The lack of systematic evidence of sorting around higher CRS thresholds (Class 5 and above) raises some interesting issues. If high-intensity participants all tended to upgrade, then insufficient data below the threshold would limit this test's ability to detect any effects. Alternatively, if high-intensity participants only upgraded at random, then no effects would be detected. The policy implications of either story are quite different, and more investigation (likely of a qualitative nature) is warranted.

\section{Conclusion}

The Community Ratings System was designed to encourage communities to build local capacity to address flood risks and become more resilient to future flood disasters. We argue that its tiered incentive structure distorts the efforts of participating communities to enhance their capacity to reduce their flood risks and become more resilient to future flood disasters. Although, previous research has found that the nonlinear incentive structure of the CRS program creates opportunities for communities participating in the CRS program to be responsive to the CRS 
incentives, no study has examined the characteristics of communities that are responding to CRS incentives. There is clear evidence of responsiveness around the thresholds to higher subsidies for the lower classes of the CRS, where the vast majority of participating communities are. While classes 6 - 9 may be disappointingly common among CRS participants, from FEMA's perspective at least the clustering above thresholds supports the case of at least modest behavior impact of CRS. At the lower end of flood mitigation efforts, communities with more passive activities, lower property values, lower peak flood risk, and lower population densities are more likely to be responsive to the system for bigger subsidies. As flood mitigation effort levels rise to the next tier, the pattern shifts such that CRS communities with more resources (and no more flood risk) are the ones responsive to CRS incentives. It is ambiguous whether the responsiveness we uncover among communities with the aforementioned characteristics is unintended or intended. The answer to this question depends on what FEMA hopes to achieve with the current CRS incentive structure.

Based on the results of this study, we offer the following recommendations. First, FEMA should invest more in tracking outcomes and base its award system (i.e., points) on evidence linking the activity to those outcomes. The relative effectiveness of informational activities, especially given their heavy use by responsive communities, merits careful attention. Additional benefit-cost analysis that identifies the additional flooding mitigation attributable to the CRS program could both demonstrate the social benefits of this program as well as potentially attract new participants. Second, it is imperative for FEMA to re-examine the incentive structure of CRS to ensure that communities that are vulnerable to the impact of floods (e.g., communities that have a high proportion of their properties in the Special Flood Hazard Area) are encouraged to participate in the CRS program. Flood mitigation incentives have been shown to have a positive impact on household decisions to adoption flood mitigation measures (Poussin et al. 2014) in addition to their positive effect on flood mitigation evidenced here. Lowering administrative costs of participation may help particularly vulnerable communities to enhance their efforts. In so doing, FEMA may be able to increase participation in the CRS program, enhance the capacity of local communities to reduce flood risks and ultimately become more resilient to future flood disasters.

An important and unexpected result is the switching of signs on payroll, income, housing value, and population density as we move from threshold 1000 to 1500 . While we do not have an overpowering theoretical rationale for this shift, this finding shows that the CRS incentive as currently designed has different appeals at different credit point thresholds. The implication is that the one-size-fits-all approach of the CRS incentive scheme has substantially different impacts for communities in classes 7 and 8 (thresholds 1000 and 1500, respectively). If FEMA's goal with the CRS incentive structure is to engender differential impacts on communities participating at varying levels/classes, then our study provides evidence to support this goal. However, if FEMA's goal is to elicit similar behavioral changes for all CRS classes, our results suggest that there might be need to recalibrate the current CRS incentive program.

These data do not allow us to examine why some CRS communities are responsive to CRS incentives or precisely estimate how much communities upgraded their score in response to the incentives. Future research would do well to further examine the drivers of community responsiveness to CRS incentives. Shedding light on the motivations and processes behind the 
strategic responses of communities can inform policy designs to boost community resilience to increasing flood risks. These results also reinforce the importance of considering local communities as strategic actors in adapting to external forces - be they national incentive programs or climate change. Community's flood mitigation efforts are not randomly assigned or independent of their expected benefits. Programs that promote those benefits can go a long way toward engendering responses from communities. If they predictably game the system, then policymakers can promote greater resilience through carefully designed incentives.

\section{References}

Brody SD, Zahran S, Highfield WE, Bernhardt, SP, Vedlitz A (2009) Policy learning for flood mitigation: A longitudinal assessment of the community rating system in Florida. Risk Analysis 29(6) 912-929. doi: 10.1111/j.1539-6924.2009.01210.x

EM-DAT: The OFDA/CRED International Disaster Database, University catholique de Louvain, Brussels, Belgium (2013) http://www.preventionweb.net/english/hazards/statistics/?hid=62. Accessed April 15, 2014

FEMA (1996) Natural disaster study: National pipeline risk index technical report (Task 2). https://www.npms.phmsa.dot.gov/data/data_natdis.htm. Accessed April 1, 2014

FEMA (2002) National flood insurance program: Program description. https://s3-us-gov-west1.amazonaws.com/dam-production/uploads/20130726-1447-20490-

2156/nfipdescrip_1_.pdf. Accessed April 6, 2014 
FEMA (2011) National flood insurance program: Answers to questions about NFIP. http://www.fema.gov/media-library-data/20130726-1438-204901905/f084_atq_11aug11.pdf. Accessed on April 16, Accessed March 26, 2014

FEMA (2013a) Community rating system: About CRS. http://www.floodsmart.gov/floodsmart/pages/crs/community_rating_system.jsp. Accessed April 16, 2014

FEMA (2013b) National Flood Insurance Program Community Rating System Coordinator's Manual. http://www.fema.gov/media-library-data/20130726-1557-204909922/crs_manual_508_ok_5_10_13_bookmarked.pdf. Accessed April 16, 2014

Guha-Sapir D, Hoyois P, Below R (2013) Annual disaster statistical review 2012: The numbers and trends. Available online: http://reliefweb.int/sites/reliefweb.int/files/resources/ADSR_2012.pdf. Accessed April 16, 2014

IPCC (2012) Managing the Risks of Extreme Events and Disasters to Advance ClimateChange Adaptation. A special report of Working Groups I and II of the Intergovernmental Panelon Climate Change. C. B. Field, V. Barros, T. F. Stocker, et al. (eds.). Cambridge, UK, Cambridge University Press. https://www.ipcc.ch/pdf/specialreports/srex/SREX_Full_Report.pdf. Accessed July 8, 2014

King RO (2013) The national flood insurance program: Status and remaining issues for congress. Congressional Research Service. http://www.fas.org/sgp/crs/misc/R42850.pdf. Accessed September 10, 2013

Kousky C, Wall M, Chu Z (2013) Flooding Resilience: Valuing Conservation Investments in a World with Climate Change. Resources for the Future Discussion Paper, RFF D P 13 -38. USA, RFF

Landry CE, Jahan-Parvar MR (2011) Flood insurance coverage in the coastal zone. J of Risk \& Insurance 78(2) 361-388

Landry CE, Li J (2012) Participation in the community rating system of NFIP: Empirical analysis of North Carolina counties. Natural Hazards Review 13, 205-220

Lee DS, Lemieux T (2010) Regression Discontinuity Designs in Economics. Journal of Economic Literature 48, 281-355

Ludy J, Kondolf GM (2012) Flood risk perception in lands "protected” by 100-year levees. Nat Hazards 61(2) 829-842. doi: 10.1007/s11069-011-0072-6 
Major DC, Bader D, Leichenko R, Johnson K, Linkin M (2014). Projecting Future Insured Coastal Flooding Damages with Climate Change. Review of Environment Energy and Economics

Mansbridge J (2013) The role of the state in governing the commons. Environmental Science and Policy 36, 8-10

Matisoff DC, Noonan DS, Mazzolini AM (2014) Performance or Marketing Benefits? The Case of LEED Certification. Environmental Science \& Technology 48(3) 2001-2007

National Weather Service (2013) United States flood loss report-water year 2012. http://www.nws.noaa.gov/hic/summaries/WY2012.pdf. Accessed April 15, 2014

Noonan D (2014) Smoggy with a chance of altruism: The effects of ozone alerts on outdoor recreation and driving in Atlanta. Policy Studies Journal 42(1) 122-145

Noonan D, Sadiq AA (Forthcoming) Flood Disaster Management Policy: An Analysis of the United States Community Ratings System. Journal of Natural Resources Policy Research

Ostrom E (1990) Governing the Commons: The Evolution of Institutions for Collective Action. Cambridge University Press

Petrolia DR, Landry CE, Coble KH (2013) Risk preferences, risk perceptions, and flood insurance. Land Econ 89(2) 227-245

Porter J (2003) Estimation in the Regression Discontinuity Model. Working Paper, Harvard University, Cambridge, MA

Posey J (2009) The determinants of vulnerability and adaptive capacity at the municipal level: Evidence from floodplain management programs in the United States. Glob Environ Change 19, 482-493

Poussin JK, Wouter Botzen WJ, Aerts JCJH (2014) Factors of influence on flood damage mitigation behaviour by households. Environmental Science \& Policy 40, 69-77

Sadiq AA (2010) Digging through disaster rubble in search of the determinants of organizational mitigation and preparedness. Risk, Hazards \& Crisis in Public Policy 1(2) 33-62. doi: 10.2202/1944-4079.1005

Sallee JM, Slemrod J (2012) Car notches: Strategic automaker responses to fuel economy policy. Journal of Public Economics 96(11) 981-999

Thistlethwaite DL, Campbell DT (1960) Regression-Discontinuity Analysis: An Alternative to the Ex Post Facto Experiment. Journal of Educational Psychology 51(6) 309-17 
United States Census Bureau (1993) Census of Population and Housing, 1990. [United States]: Summary Tape File 3C. ICPSR06054-v1. Ann Arbor, MI: Inter-university Consortium for Political and Social Research [distributor]. doi:10.3886/ICPSR0654.v1

United States Department of Commerce (2008) Bureau of the Census. Census of Governments. [United States]: Finance Statistics, 1992. ICPSR04420.v1. Ann Arbor, MI: Interuniversity Consortium for Political and Social Research [distributor]. doi: 0.3886/ICPSR04420.v1

Zahran S, Weiler S, Brody SD, Lindell MK, Highfield WE (2009) Modeling national flood insurance policy holding at the county scale in Florida, 1999-2005. Ecological Economics 68(10) 2627-2636

Zahran S, Brody SD, Highfield WE, Vedlitz A (2010) Non-linear incentives, plan design, and flood mitigation: The case of the federal emergency management agency's community rating system. J of Environ Planning and Management 53(2) 219-239 